\title{
Protective effects of hesperidin in experimental testicular ischemia/reperfusion injury in rats
}

\author{
Emrah Celik ${ }^{1}$, Hakan Oguzturk² Nurhan Sahin ${ }^{3}$, Muhammet Gökhan Turtay², Fatih Oguz ${ }^{4}$, \\ Osman Ciftci ${ }^{5}$
}

\author{
${ }^{1}$ Hospital of Seka, Emergency Service, Izmit, Turkey \\ ${ }^{2}$ Emergency Department, Inonu University, Malatya, Turkey \\ ${ }^{3}$ Department of Pathology, Inonu University, Malatya, Turkey \\ ${ }^{4}$ Urology Department, Inonu University, Malatya, Turkey \\ ${ }^{5}$ Department of Pharmacology, Inonu University, Malatya, Turkey
}

Submitted: 22 April 2014

Accepted: 22 June 2014

Arch Med Sci 2016; 12, 5: 928-934

DOI: $10.5114 /$ aoms.2015.47697

Copyright @ 2015 Termedia \& Banach

\section{Abstract}

Introduction: In this study, we aimed to determine the protective effects of hesperidin, a citrus flavonoid, in a model of testicular ischemia/reperfusion injury in rats.

Material and methods: Forty-two pubertal male Wistar-Albino rats were divided into six groups: group 1 - control; group $2-50 \mathrm{mg} / \mathrm{kg}$ hesperidin (low dose hesperidin) used without torsion (LH group); group $3-100 \mathrm{mg} / \mathrm{kg}$ hesperidin without torsion (HH group); group 4 - torsion/detorsion group (T/D); group $5-\mathrm{T} / \mathrm{D}+50 \mathrm{mg} / \mathrm{kg}$ hesperidin treatment group (T/D + LH); and group $6-T / D+100 \mathrm{mg} / \mathrm{kg}$ hesperidin treatment group $(T / D+H H)$. Hesperidin was given to the treatment groups 30 min before detorsion. After the fourth hour of reperfusion, orchiectomy was performed on the rats under anesthesia. The tissue samples were examined histologically and biochemically.

Results: In the T/D group testicular malondialdehyde (MDA) levels were increased significantly $(p<0.001)$ whereas superoxide dismutase (SOD), catalase (CAT) and glutathione (GSH) levels were decreased compared to the control and other groups. However, hesperidin caused the effect of T/D to become closer to normal biochemical values. In addition, the histological examinations showed that T/D caused damage in the testis but hesperidin reduced this effect. The effects of hesperidin were found to be dose dependent. Thus, applying high doses would generate greater therapeutic effects. Conclusions: In a rat testicular T/D model we observed biochemical and histological damage due to ischemia. However, high and low dose applications of hesperidin were shown to have protective effects against this damage. Therefore, the aforementioned citrus flavonoid may provide positive results in cases of testicular torsion.

Key words: hesperidin, testicular torsion-detorsion, ischemia-reperfusion injury in the rat.

\section{Introduction}

Testicular torsion is an acute surgical emergency that causes severe acute ischemia when the spermatic cord is folded. It can be seen at any age and requires urgent diagnosis and treatment. A significant portion of the patients are children and young men [1].
Corresponding author: Hakan Oguzturk Assoc. Prof. Emergency Department Inonu University 44150 Malatya, Turkey Phone: +90 5535924026 E-mail: oguzturk@hotmail.com 
Although the most significant complication of testicular torsion is gonad infarction, abnormal semen analysis and apoptosis in the reperfused testis are also seen [1,2]. Therefore patients should be told about the risk of subfertility.

Testicular torsion causes ischemic injury while detorsion causes reperfusion injury, which creates structural and biochemical changes in the tissue [3]. Reperfusion injury is associated with increase of free oxygen radicals and neutrophil infiltration. Radicals cause cell membrane lipid peroxidation, protein denaturation and DNA damage [4].

In experimental studies, dehydroepiandrosterone, diclofenac, $\mathrm{N}$-acetylcysteine, morphine, allopurinol, melatonin, caffeic acid and many other pharmacological agents have been used to avoid detorsion damage [4-10].

Hesperidin is a significant and effective antioxidant as compared to other flavonoids [11-14]. Although research has been performed regarding ischemia/reperfusion injury associated with antioxidant activity in many tissues [12-14], there are no data about the protective effect of hesperidin against damage after ischemia-reperfusion in testis torsion. Therefore, in this study, we aimed to investigate the biochemical and histological damage caused by testicular torsion/detorsion and the protective effect of hesperidin. Biochemical evaluation of malondialdehyde (MDA), superoxide dismutase (SOD), catalase (CAT) and glutathione (GSH) was performed, and testicular tissue samples were also evaluated.

\section{Material and methods}

The study protocol was approved by the Ethics Committee of the Inonu University Committee on
Animal Rights (2011/A-64) and was carried out in the Inonu University Experimental Animal Production and Application Center.

In this study, 42 male Wistar-Albino rats, average weight $280 \mathrm{~g}$ (range: 250-300 g), were used. Rats were treated in standard plastic cages at a constant temperature $\left(21^{\circ} \mathrm{C}\right)$ in an air-conditioned experimental animal laboratory. Before the study, there were no restrictions on water or diet. All rats were treated in a controlled environment in terms of heat and light, and given standard water and food. A heating lamp was used during the study for the prevention of hypothermia.

\section{Study groups and experimental design}

On the day of the experiment, the Wistar-Albino rats were randomly categorized into a total of six groups, each group containing seven rats. All groups were anesthetized with xylazine/ketamine. After that, the right testicle and spermatic cord were dissected via a right scrotal incision.

In the next step, the right testis was rotated $720^{\circ}$ clockwise for torsion in the testicular torsion groups. In order to maintain the torsion of the testis, tunica albuginea was fixed to the scrotum with a silk suture. The torsion and detorsion protocols lasted for $5 \mathrm{~h}$. Right testis orchiectomy was performed at the end of the protocol. Hesperidin was dissolved in carboxymethyl cellulose (CMC) at a $0.1 \%$ concentration and given to the treatment groups via the intraperitoneal method at the $30^{\text {th }}$ minute of torsion. The $0.1 \%$ CMC solution was given to the control groups intraperitoneally.

The study groups of rats are shown in Table I.

Table I. Study groups

\begin{tabular}{|c|c|c|}
\hline Groups & $\begin{array}{c}\text { Number } \\
\text { of subjects }(n)\end{array}$ & Experimental protocol \\
\hline Group 1: control & 7 & $\begin{array}{l}\text { Surgical procedures performed, right testis removed and placed again the } \\
\text { scrotum without application of torsion. This group was used to determine } \\
\text { possible effects of surgical stress on the testes. }\end{array}$ \\
\hline Group 2: LH & 7 & $\begin{array}{l}\text { Surgical procedures performed, right testis removed and } 50 \mathrm{mg} / \mathrm{kg} \text { i.p. } \\
\text { hesperetin was given without application of torsion and placed again. This } \\
\text { group was used to determine possible effects of low-dose hesperetin. }\end{array}$ \\
\hline Group 3: $\mathrm{HH}$ & 7 & $\begin{array}{l}\text { Surgical procedures performed, right testis removed and } 100 \mathrm{mg} / \mathrm{kg} \text { i.p. } \\
\text { hesperetin was given without application of torsion and placed again. This } \\
\text { group was used to determine possible effects of high-dose hesperetin. }\end{array}$ \\
\hline Group 4: T/D & 7 & $\begin{array}{l}\text { Right testis removed and testicular torsion was applied. After a period of } \\
1 \mathrm{~h} \text { ischemia detorsion was applied and } 4 \mathrm{~h} \text { of reperfusion was achieved. This } \\
\text { group was used to determine possible effects of detorsion on I/R injury. }\end{array}$ \\
\hline Group 5: T/D + LH & 7 & $\begin{array}{l}\text { Right testis removed and testicular torsion was applied. After a period of } 1 \mathrm{~h} \\
\text { ischemia detorsion was applied and } 4 \mathrm{~h} \text { of reperfusion was achieved. } 50 \mathrm{mg} / \\
\mathrm{kg} \text { i.p. hesperetin was given } 30 \mathrm{~min} \text { before detorsion. This group was used } \\
\text { to determine possible effects of } 50 \mathrm{mg} / \mathrm{kg} \text { hesperetin on testicular I/R injury. }\end{array}$ \\
\hline Group 6: T/D + HH & 7 & $\begin{array}{l}\text { Right testis removed and testicular torsion was applied. After a period of } 1 \mathrm{~h} \\
\text { ischemia detorsion was applied and } 4 \mathrm{~h} \text { of reperfusion was achieved. } 100 \mathrm{mg} / \\
\mathrm{kg} \text { i.p. hesperetin was given } 30 \mathrm{~min} \text { before detorsion. This group was used to } \\
\text { determine possible effects of } 100 \mathrm{mg} / \mathrm{kg} \text { hesperetin on testicular I/R injury. }\end{array}$ \\
\hline
\end{tabular}




\section{Biochemical assays}

The homogenization of tissues was carried out in a Teflon glass homogenizer in $150 \mathrm{mM} \mathrm{KCl}$ $(\mathrm{pH} 7.4)$ to obtain a $1: 10(\mathrm{w} / \mathrm{v})$ dilution of the entire homogenate. The homogenates were centrifuged at $18,000 \mathrm{~g}\left(4^{\circ} \mathrm{C}\right)$ for $30 \mathrm{~min}$ and at $25,000 \mathrm{~g}$ for $50 \mathrm{~min}$. The levels of MDA, as an index of lipid peroxidation, were determined via thiobarbituric acid reaction using the method of Yagi [15]. The product was evaluated spectrophotometrically at $532 \mathrm{~nm}$, and the results were expressed as nanomoles per gram of tissue. The reduced GSH content of the kidney homogenate was measured at $412 \mathrm{~nm}$ using the method of Sedlak and Lindsay [16] and expressed as nanomoles per milliliter of tissue. Copper-zinc SOD activity was measured via the inhibition of nitroblue tetrazolium reduction due to $\mathrm{O}_{2}$ generated by the xanthine/xanthine oxidase system [17]. The product was evaluated spectrophotometrically at $560 \mathrm{~nm}$, and the results were expressed as units per milligram of protein. The CAT activity levels of the tissues were determined according to the method of Aebi [18]. The enzymatic decomposition of $\mathrm{H}_{2} \mathrm{O}_{2}$ was directly followed by a decrease in absorbance at $240 \mathrm{~nm}$. The enzyme activities were expressed as $\mathrm{k} / \mathrm{mg}$ of protein. Tissue protein content was determined according to the method developed by Lowry et al. [19] using bovine serum albumin as a standard.

\section{Histological analysis}

In the testicles exposed to ischemia during torsion, color changes were observed due to edema and venous stasis. In the testes given detorsion, improvement was observed in the color of the testes in a short time. The testicular tissue samples were sent to a pathology laboratory in $10 \%$ formaldehyde. Macroscopically sampled tissues were embedded in paraffin and 5-micron thick sections were cut after routine tissue processing. Sections were stained using a hematoxylin eosin staining procedure and then evaluated via light microscopy. Microscopically, an assessment of the presence/ absence of edema, congestion and hemorrhage was performed, and changes in the seminiferous tubules and germinal cells were graded according to the classification of Cosentino et al. [20].

Grading criteria for the histopathologic findings:

Grade I: normal testicular tissue.

Grade II (low impact): loss of cohesion in germinal cells, tightening of the seminiferous tubules.

Grade III (moderate impact): irregular, dispersed, shrunken germinal cells, pyknotic nuclei, impaired borders of the seminiferous tubules.

Grade IV (severe impact): irregular, damaged seminiferous tubules filled with coagulation necrosis in germ cells.

\section{Statistical analysis}

The Statistical Package for the Social Sciences 15.0 (SPSS 15.0, Chicago, IL, USA) for Windows was used for data analysis. A one-way ANOVA test was used to compare the groups; to detect differences between groups, a post doc Duncan's test was applied. A value of $p<0.001$ was considered significant.

\section{Results}

\section{Biochemical results}

The levels of SOD, CAT, GSH and MDA for the rat testes are given in Table II. MDA values in the T/D group were significantly increased compared to those of the hesperidin and control groups $(p<0.001)$. Tissue MDA levels were found to be decreased in the T/D + LH and T/D + HH groups. In addition, dose-dependent MDA level differences were not observed between groups 2 and 3 or 5 and 6 .

Testicular GSH, SOD and CAT enzyme activity levels were significantly decreased in the T/D

Table II. Distribution of biochemical data by group

\begin{tabular}{|c|c|c|c|c|}
\hline Groups & $\begin{array}{c}\text { MDA } \\
\text { [nmol/g tissue] }\end{array}$ & $\begin{array}{c}\text { SOD } \\
\text { [U/mg protein] }\end{array}$ & $\begin{array}{c}\text { CAT } \\
{[\mathrm{k} / \mathrm{mg} \text { protein] }}\end{array}$ & $\begin{array}{c}\text { GSH } \\
{[\mathrm{nmol} / \mathrm{ml}]}\end{array}$ \\
\hline Group 1: control & $7.67 \pm 0.97$ & $3.86 \pm 0.17$ & $0.037 \pm 0.001$ & $390.1 \pm 18.0$ \\
\hline Group 2: LH & $6.63 \pm 0.55$ & $3.83 \pm 0.39$ & $0.027 \pm 0.003^{*}$ & $432.4 \pm 10.3$ \\
\hline Group 3: HH & $4.64 \pm 0.39^{*}$ & $4.73 \pm 0.43^{*}$ & $0.030 \pm 0.001^{*}$ & $436.3 \pm 14.2$ \\
\hline Group 4: T/D & $11.73 \pm 0.59^{*, * *}$ & $1.80 \pm 0.24^{*, * \star}$ & $0.017 \pm 0.001^{*, * *}$ & $311.3 \pm 12.4^{*}$ \\
\hline Group 5: T/D + LH & $6.48 \pm 0.26$ & $2.70 \pm 0.23^{*, * * *}$ & $0.025 \pm 0.001^{*}$ & $385.3 \pm 19.4$ \\
\hline Group 6: T/D + HH & $6.66 \pm 0.83$ & $3.65 \pm 0.26$ & $0.030 \pm 0.002^{*}$ & $380.5 \pm 16.8^{\#}$ \\
\hline Value of $p$ & 0.001 & 0.001 & 0.001 & 0.001 \\
\hline
\end{tabular}

*Indicates means significantly different from control group ( $<<0.05) ;{ }^{* *}$ indicates significant difference between group 4 and other treatment groups; ${ }^{* *}$ indicates significant difference between group 5 and other treatment groups. "Indicates significant difference between group 6 and other treatment groups. 
treated group $(p<0.001)$. A significant difference in the SOD enzyme activity levels was observed in groups 5 and 6 ( $p<0.001)$; however, differences in GSH and CAT levels were insignificant.

\section{Histopathological results}

Histopathologically, the rats in the control group had essentially normal seminiferous tubule morphology (Figure 1). In the T/D group (group 4), the lesions varied among grades 2 (Figures 2 and 3), 3 and 4 . In this group edema, congestion hemorrhage between the seminiferous tubules and necrosis of the germinal cells were the predominant features in the sections (Figures 4-7). When the $\mathrm{T} / \mathrm{D}-\mathrm{HH}$ and T/D groups were compared, in the $\mathrm{T} / \mathrm{D}-\mathrm{HH}$ group, grade 1 was found to be increased (3/7) and grade 3-4 injury was found to be decreased (0/7).

In the T/D group, various pathology grade changes in the seminiferous tubules were observed. In addition, grade 4 injury was only observed in the T/D group. Histopathological evaluation of the findings are shown in Table III.

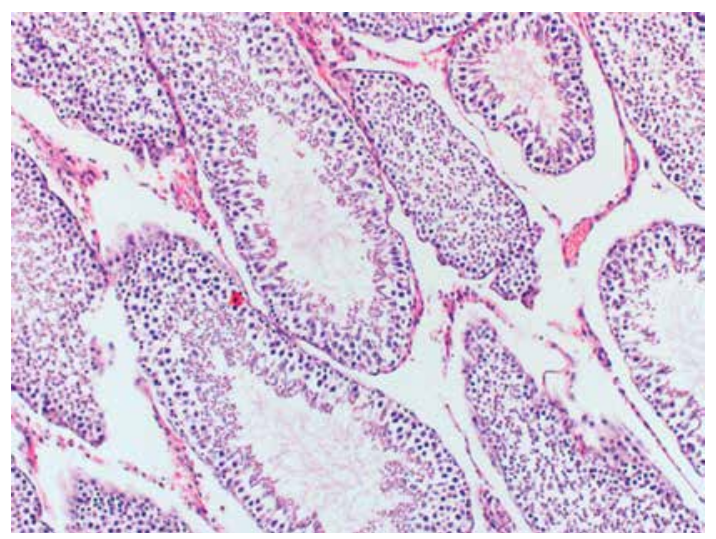

Figure 2. T/D-LH Group. Grade II testicular changes with narrow atrophied seminiferous tubules. $(\mathrm{H}+\mathrm{E}$, $100 x)$

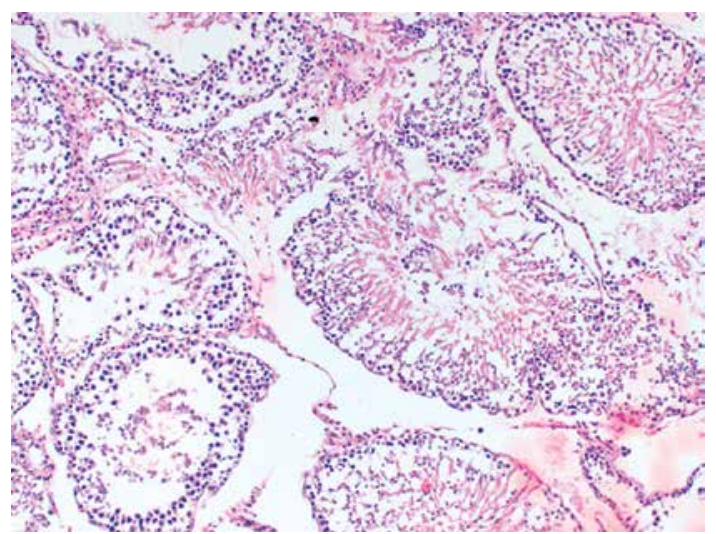

Figure 4. T/D-LH Group. Unclear boundaries of seminiferous tubule, irregular, dispersed germinal cells (grade III) $(H+E, 100 x)$

\section{Discussion}

Testicular torsion is typically seen in young men and is characterized by a loss of circulation due to the testicular vascular pedicle turning around. It is a urological emergency that can result in the loss of the related gonad [21].

Edema, hemorrhage and arterial obstruction develop due to the deterioration of venous drainage during testicular detorsion/torsion, and tissue

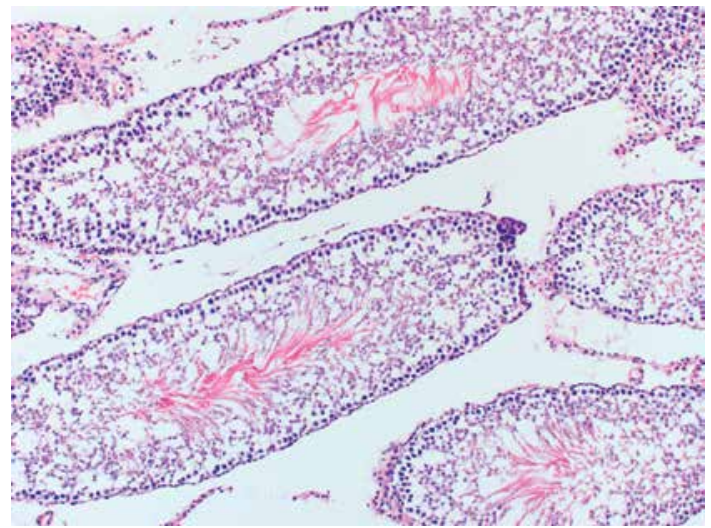

Figure 1. Control group shows normal testicular seminiferous tubules and germinal cells $(H+E, 200 x)$
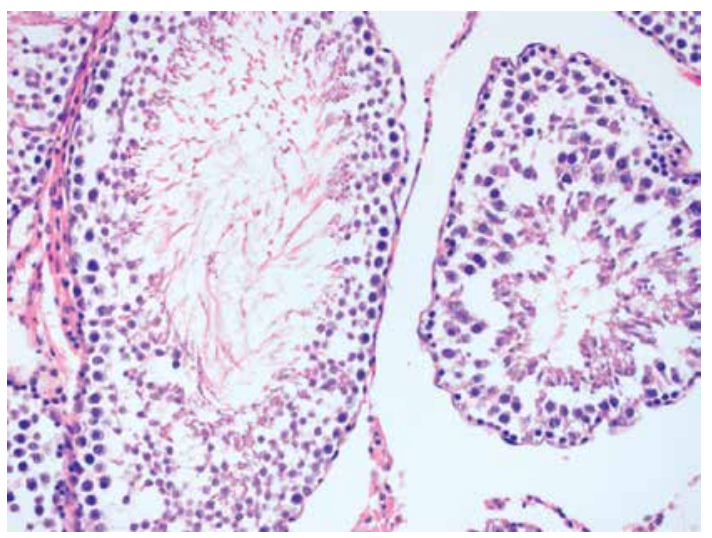

Figure 3. T/D-HH Group Grade II testicular tissue showing obvious loss of cohesion $(H+E, 200 x)$

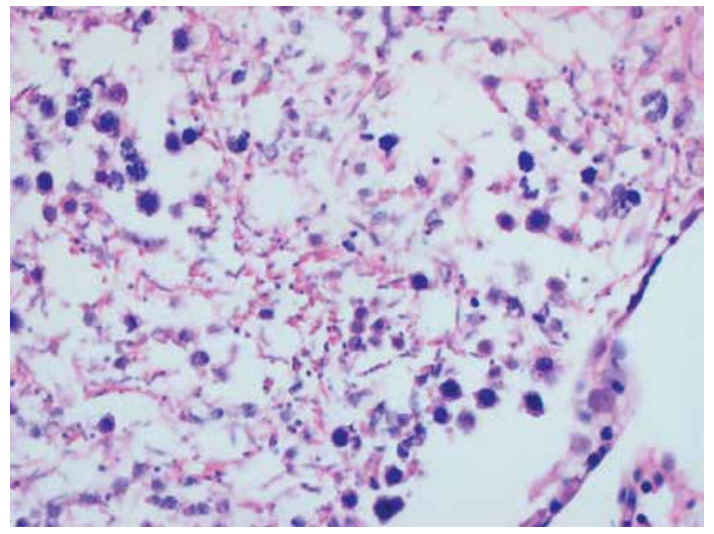

Figure 5. T/D Group. Dispersed, collapsed cells, pyknotic nuclei in the seminiferous tubule (grade III) $(\mathrm{H}+\mathrm{E}, 400 \times)$ 


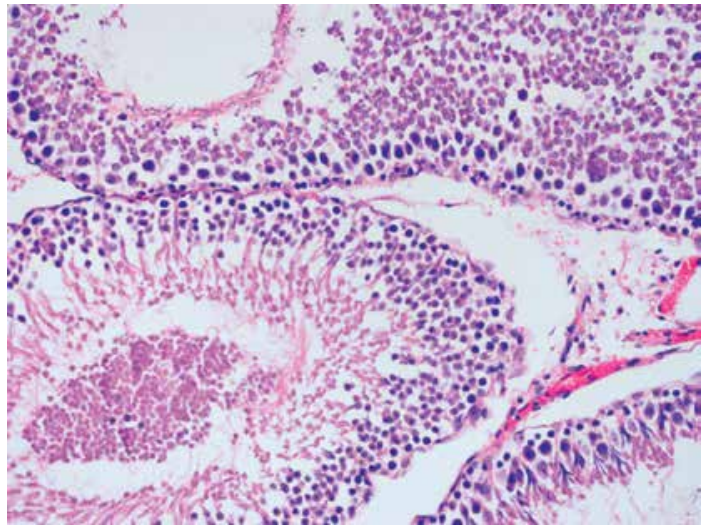

Figure 6. T/D Group. Grade IV changes in the seminiferous tubules with significant coagulative necrosis $(H+E, 200 x)$

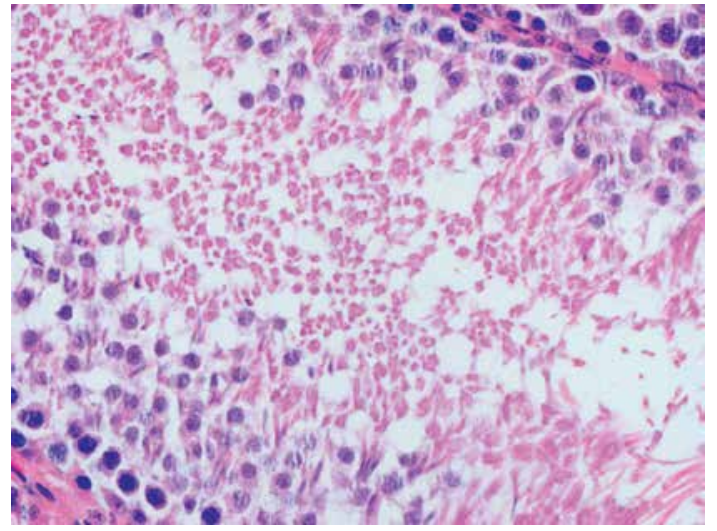

Figure 7. T/D Group. Significant coagulative necrosis in germinal cells (Grade IV) $(H+E, 400 x)$

Table III. Histopathological evaluation of the findings

\begin{tabular}{|lcccccc|}
\hline Groups & Grade 1 & Grade 2 & Grade 3 & Grade 4 & Edema & Congestion \\
\hline Group 1: control & $7 / 7$ & $0 / 7$ & $0 / 7$ & $0 / 7$ & $6 / 7$ & $0 / 7$ \\
\hline Group 2: $\mathrm{LH}$ & $0 / 7$ & $0 / 7$ & $0 / 7$ & $0 / 7$ & $0 / 7$ & $0 / 7$ \\
\hline Group 3: $\mathrm{HH}$ & $0 / 7$ & $0 / 7$ & $0 / 7$ & $0 / 7$ & $0 / 7$ & $0 / 7$ \\
\hline Group 4: T/D & $0 / 7$ & $2 / 7$ & $1 / 7$ & $4 / 7$ & $5 / 7$ & $2 / 7$ \\
\hline Group 5: T/D-LH & $0 / 7$ & $5 / 7$ & $2 / 7$ & $0 / 7$ & $4 / 7$ & $3 / 7$ \\
\hline Group 6: T/D-HH & $3 / 7$ & $3 / 7$ & $1 / 7$ & $0 / 7$ & $4 / 7$ & $3 / 7$ \\
\hline
\end{tabular}

ischemia occurs due to a decrease in blood flow. Previous studies have shown that in $720^{\circ}$ torsion, blood flow stops irreversibly, and complete ischemia occurs [22]. Akgür et al. [23] found that in their rat model of $720^{\circ}$ unilateral left testis torsion, reperfusion injury developed biochemically up to $5 \mathrm{~h}$ after detorsion. Cosentino et al. [20] determined that after $3 \mathrm{~h}$ of $720^{\circ}$ torsion, testicular blood flow will not return, and serious changes such as tissue necrosis are seen. Also, irreversible injury and necrosis have been observed in the testicles after $2 \mathrm{~h}$ of arterial or $6 \mathrm{~h}$ of venous obstruction [23]. Turner et al. [24] found that lipid peroxidation is significantly increased after $4 \mathrm{~h}$ of reperfusion. Akgür et al. [25] also obtained results that were consistent with Turner's study. On the whole, at least $4-5 \mathrm{~h}$ of $720^{\circ}$ torsion causes enough testicular tissue injury ischemic effect in testis in rats. In our study testes were exposed after $1 \mathrm{~h}$ of torsion and $4 \mathrm{~h}$ of detorsion. The basic mechanism of ischemia-induced tissue damage due to oxidative stress has been shown in recent studies. The testes are highly sensitive to oxidative stress due to their physiological and anatomical structures. Therefore, serious oxidative damage occurs due to ischemia and reperfusion after torsion, and a reduction in lifetime reproductive function and efficiency has been reported in adolescents [25]. Tissue lipid peroxide content is the most import- ant indicator of ischemia/reperfusion (I/R), and the best way to demonstrate this is via MDA level measurement. Studies show that as the duration of testis I/R increases, this significantly increases testicular tissue MDA levels, which causes oxidative damage $[6,9,25,26]$. Erdemir et al. found that MDA levels increased significantly in the torsion group as compared to the control group [9]. Likewise, Bozlu et al. [27] reported that MDA levels in testicular tissue increased $4 \mathrm{~h}$ after the start of reperfusion. However, SOD and CAT enzyme levels, which are one of the antioxidant defense systems in testicular tissue, and GSH levels were decreased significantly compared to the control and other groups. In their study, Raju et al. observed that MDA levels in the T/D group were increased compared to those in the treatment groups [26].

Although there are many studies on the treatment of testicular torsion, none of them used hesperidin. Today, hesperidin is used as a microcapillary regulator in varicose veins and hemorrhoids. Schoab et al. showed that in patients with chronic venous insufficiency, diosmin-hesperidin promotes wound healing and shortens recovery time [28]. In their meta-analysis, Trent et al. [29] found that in patients with chronic venous insufficiency, in addition to conventional therapy, the administration of diosmin-hesperidin was rapidly effective 
in reducing the symptoms associated with ulcers and ulcer size when compared to those treated with only conventional therapy.

In our study, hesperidin applications in both high and low doses reduced the level of MDA, which is increased due to torsion, and SOD, CAT and GSH levels were found to increase to some degree. These results show that hesperidin may reverse the oxidative damage induced by torsion via its antioxidant properties.

Interstitial edema develops during the early stages of testicular torsion [27]. In our study, the first changes, such as edema and congestion, were observed after torsion. This may indicate that venous circulation is responsible for any damage caused by testicular torsion. A histopathological evaluation was performed according to the classification of Cosentino et al. [20]. In our study, all of the rats in the control group are in grade 1 , while the histopathological evaluation of testicular tissue damage in the testicular torsion group showed grade 2, 3 and 4 damage, indicating that a torsion model was achieved. At the end of all experiments, hemorrhage-dependent color variation was observed via macroscopy in the testicles to which torsion was applied. Vascular congestion and edema were observed in the early postoperative period due to sudden changes in circulation. This may have been because testicular torsion initially collapses the veins and arteries, ultimately resulting in edema, which could cause hemorrhagic infarction or ischemia in the testis. In our study, Stage 4 damage was only observed in the T/D group. T/D-LH and T/D-HH groups were compared with the T/D group; there was no severe pathological effects, and the degree of damage was lower in the hesperidin-treated groups (Figures 2 and 3). This demonstrated the protective effect of hesperidin.

In conclusion, in this study, hesperidin, an antioxidant and anti-inflammatory agent, and its effect on ischemia-reperfusion injury due to testicular torsion-detorsion were studied for the first time. This drug was administered to two groups, in two different doses; the MDA levels of both groups were found lower when compared to that of the I/R group. These data show that hesperidin reduces the effects of I/R damage in the setting of $T / D$. In the hesperidin group, the degree of damage was found to be lower. Therefore hesperidin could be used as a novel agent in the treatment of ischemia/reperfusion injury due to testicular torsion. However, further studies are needed to verify these results.

\section{Acknowledgments}

This research was supported by the Inonu University Scientific Research Project.

\section{Conflict of interest}

The authors declare no conflict of interest.

\section{References}

1. Prillaman HM, Turner TT. Rescue of testicular function after acute experimental torsion. J Urol 1997; 157: 340-5.

2. Cay A, Alver A, Kücük M, et al. The effects of N-acetylcysteine on antioxidant enzyme activities in experimental testicular torsion. J Surg Res 2006; 131: 199-203.

3. Cuzzocrea S, Riley DP, Caputi AP, Salvemini D. Antioxidant therapy: a new pharmacological approach in shock, inflammation, and ischemia/reperfusion injury. Pharmacol Rev 2001; 53: 135-59.

4. Aksoy H, Yapanoglu T, Aksoy Y, et al. Dehydroepiandrosterone treatment attenuates reperfusion injury after testicular torsion and detorsion in rats. J Pediat Surg 2007; 42: 1740-4.

5. Mogilner JG, Lurie M, Coran AG, et al. Effect of diclofenac on germ cell apoptosis following testicular ischemia-reperfusion injury in a rat. Pediatr Surg Int 2006; 22: 99-105.

6. Aydıner CY, Pul M, Inan M, Bilgi S, Çakır E. Can N-acetylcysteine play a role on preventing tissue damage on experimental testicular torsion. Cum Med J 2012; 34: 462-71.

7. Salmasi AH, Beheshtian A, Payabvash S, et al. Effect of morphine on ischemia-reperfusion injury: experimental study in testicular torsion rat model. Urology 2005; 66: 1338-42.

8. Akgur F, Kilinc K, Aktug T, Olguner M. The effect of allopurinol pretreatment before detorting testicular torsion. J Urol 1994; 151: 1715-7.

9. Erdemir F, Parlaktaş BS, Özyurt H, et al. Antioxidant effect of melatonin in systemic circulation of rats after unilateral testicular torsion. Turk J Med Sci 2008; 38: $1-6$.

10. Uz E, Sogut S, Sahin S, et al. The protective role of caffeic acid phenethylester on testicular tissue after testicular torsion and detorsion. World J Urol 2002; 20: 264-70.

11. Shagirtha K, Pari L. Hesperedin, a citrus flavonone, protects potentially cadmium induced oxidative testicular dysfunction in rats. Ecotoxicol Environ Saf 2011; 74: 2105-11.

12. Ünlü A, Sucu N, Tamer L, et al. Effects of Daflon on oxidative stress induced by hind limb ischemia/reperfusion. Pharmacol Res 2003; 48: 11-5.

13. Chiou GC, Xu XR. Effects of some natural flavonoids on retinal function recovery after ischemic insult in the rat. J Ocul Pharmacol Ther 2004; 20: 107-13.

14. Gaur V, Kumar A. Hesperidin pre-treatment attenuates NO-mediated cerebral ischemic reperfusion injury and memory dysfunction. Pharmacol Rep 2010; 62: 635-48.

15. Yagi K. Simple assay for the level of total lipid peroxides in serum or plasma. Meth Mol Biol 1998; 108: 101-6.

16. Sedlak J, Lindsay RH. Estimation of total, protein bound, and nonprotein sulfhydryl groups in tissue with Ellman's reagent. Anal Biochem 1968; 25: 192-205.

17. Sun Y, Oberley LW, Li YA. Simple method for clinical assay of superoxide dismutase. Clin Chem 1988; 34: 497-500.

18. Aebi H. Catalase. In: Bergmeyer HU (ed.). Methods of enzymatic analysis. Academic Press. New York 1974; 673-77.

19. Lowry OH, Rosebrough NJ, Farr AL, Randall RI. Protein measurement with folin phenol reagent. J Biol Chem 1951; 193: 265-75. 
20. Cosentino MJ, Nishida M, Rabinowitz R, Cockett ATK. Histological changes occurring in the contralateral testes of prepubertal rats subjected to various durations of unilateral spermatic cord torsion. J Urol 1985; 133: 906-11.

21. Barada IH, Weingarten JL, Cromie WJ. Testicular salvage and age-related delay in the presentation of testicular torsion. J Urol 1989; 142: 746-8.

22. Hutson JM. Undecended testis, torsion and varicocele. In: Pediatric surgery. O'Neill JA, Rowe MI, Grosfeld JL, et al. (eds.). Mosby, St. Louis 1998; 1087-109.

23. Akgür FM, Kılınç K, Aktuğ T. Reperfusion injury after detorsiyon of unilateral testicular torsion. Urol Res 1993; 21: 395-9.

24. Turner TT, Tung KS, Tomomasa H, Wilson LW. Acute testicular ischemia results in germ cell-specific apoptosis in the rat. Biol Reprod 1997; 57: 1267-74.

25. Akgür FM, Kılıç K, Tanyel FC, Büyükpamukçu N, Hiçsönmez A. Ipsilateral and contralateral testicular biochemical acute changes after unilateral testicular torsion and detorsion. Urology 1994; 44: 413-8.

26. Raju AB, Challa SR, Akula A, Kiran K, Harinadh GB. Evaluation of oxidant and anti-oxidant balance in experimentally induced testicular injury by ischemia reperfusion in rats. Eur J Gen Med 2011; 8: 117-21.

27. Bozlu M, Coskun B, Cayan S, et al. Inhibition of poly (adenosine diphosphata-ribose) polymerase decreases longterm histologic damage intesticular ischemia-reperfusion injury. Urology 2004; 63: 791-5.

28. Schoab SS, Porter J, Scurr JH, Coleridge Smith PD. Endotelial activation response to oral micronised flavanoid therapy in patients with chronic venous disease - a prospective study. Eur J Vasc Endovasc Surg 1999; 17: 313-8.

29. Trent JT, Falobella A, Kirsner RS, Eaglstein WH. Venous ulcer pathophysiology and treatment option. Ostomy Wound Manage 2005; 51: 38-54. 